\title{
Research on the teaching mode of College English listening teaching model based on Network
}

\author{
LI Zhaoying ${ }^{1, \text { a }}$ \\ ${ }^{1}$ Jilin Business and Technology College, Changchun 130000,China \\ aemail: lizhaoying@163.com
}

Keywords: Network; integration; College English; teaching model

\begin{abstract}
With the extensive use of the network in people's daily life, the computer and other multimedia aided devices have been widely used in our study. As is known to all, multimedia and network technology can provide friendly interface, visual image interactive learning environment, can provide graphic audio-visual articals variety of sensory stimulation, can according to hypertext, hyperlink way of organization and management of knowledge and a variety of teaching information, in Internet organized by way of the construction of the knowledge base, information base voluminous, has become the biggest source of information in the world. The integration of information technology and subject teaching has become a new viewpoint of College English teaching reform.
\end{abstract}

\section{Introduction}

The College English Curriculum Requirements (for Trial Implementation) "pointed out:" in view of the rapidly increasing the number of college students and the relatively limited education resources, we should make full use of multimedia and network technology development brings opportunity and adopt new teaching mode reform of the original with the teacher taught the unitary teacher centered pattern. The new teaching model should be supported by modern information technology, especially network technology, so that English teaching can not be restricted by the time and place of learning, active learning." How to make full use of the advanced technical means in the traditional classroom teaching, so that the two can be well integrated together. People have come to realize that to make them really organically, not only simple sense means change, the more important is a shift in concept and theory, in theory for its application in order to find the theoretical support, and combined with the practice in teaching methods, means, teaching mode as the main entry point for new changes. Taking this as a starting point, this paper discusses how to apply the network to English Teaching in combination with the practice of College English teaching[1].

\section{The theory of network teaching}

Constructivism is an important branch of cognitive theory, is the 20th century, since the late 1980s and early 1990s, the rise of a new concept of learning, learning theory of behaviorism and cognitivism the further development of the. Constructivism from

With the development of modern information technology, especially the network technology has been widely used, a kind of English listening teaching mode based on campus network - "zero" teaching mode. This teaching model has two meanings. First, no longer use the specialized time to open the hearing class, but to take "has the curriculum to have the teacher not to have the class" the teaching mode. Students through learning autonompus, teachers through monitoring, assessment to achieve the teaching purpose of a process. Holec self defined as "responsible for their own learning ability". Dickinson is that is the attitude of a learner to his or her learning about all the decisions, and these decisions responsible for implementation. They all emphasize that learners should have the courage to take the responsibility of their own learning, not passively accept knowledge, but in accordance with their own willingness to actively and creatively to seek knowledge. Second, because it is not restricted by time and place, students can through the language laboratory, network 
and broadcast from time to time, to carry out independent learning, completely out of the "class" of the shackles. It is a kind of teaching mode which takes the students to develop autonomous learning as the center, to improve the students' ability as the goal, to cultivate the ability of self-study, and to standardize the management, monitoring and evaluation.

The biggest difference between the teaching mode and the traditional mode of teaching is: the former is centered on students, teachers just study monitoring, coaching and administrative person. It is also give consideration to the students' individual differences, to maximize play students' enthusiasm for learning and autonomy, the maximum improve the learning efficiency.

Zero hour is a product of the development of the times, but it is not blind, it also has a solid theoretical basis. The humanism teaching theory represented by Maslow and Rodgers provides a theoretical basis for the teaching reform of zero hour of listening. Humanism learning theory emphasizes that learning motivation and significance of the study, under the guidance of the teaching characteristics: teaching should give full play to the each student's "potential", pay attention to the development of students' personality, to cultivate students' learning enthusiasm, initiative, independence and creativity, cultivating students' ability, so that they can continuously acquire new knowledge, to explore new problems, in the middle school will self evaluation, so as to achieve the teaching effect of "self realization".

At the beginning of the sixties of the 20th century Swiss child psychiatrist Piaget's cognitive development theory argues that the formation and development of cognition is a constructing process, the learner is in the interaction of the surrounding environment and gradually construct knowledge, so that their cognitive structure development. Today the constructivism holds that knowledge is not taught by teachers, but the learner in a certain situation and social cultural background, with the help of others (including teachers and learning partners) help, use the necessary learning resources, through the construction of meaning is obtained; learning is a process that learners construct the internal mental representation the initiative, which includes not only the structural knowledge, but also a large number of non structural background experience; students are the main body of information processing, significance of the initiative is to construct, rather than passive external stimuli recipient and the subject of education; the teacher is to help the construction of meaning, rather than the promoter, the dissemination of knowledge and students; "situation", "cooperation", "conversation" and "meaning construction" is the four elements of learning environment. Learning is a process, the learner is not a passive accept stimulation[2], but learners actively construct the internal psychological structure, namely learners according to their own needs, interests, hobbies, the cognitive structure of the original selection of the active external information, plus the process of industry and trade and processing. Learning is a process of negotiation activities. The development of learning is to learn the original cognitive structure of individual based, different students from different cognitive structure and the formation of knowledge in different understanding, at this time only through the "negotiation" to reach a consensus. Learning is a kind of embodiment of the real situation. Students can only be in the real situation really apply the knowledge to solve real world problems. On the teaching mode, constructivism advocates "learning centered" and "student-centered", the traditional "teaching centered" and "Teacher centered" traditional teaching mode to the challenge. Constructivist learning theory core is summed up in: student-centered, emphasizing students' active exploration of knowledge, active discovery and construction of knowledge significance. It believes that knowledge is not taught by teachers, but students in certain situations that social and cultural background, with the help of other people (including teachers and learning partners), use the necessary learning materials, through the construction of meaning and obtained. Constructivism advocates with cognitive law of English learners. With the rapid development of modern network technology today, with the construction of Marxist theory and practice of English Teaching in higher vocational colleges have become increasingly close, become the main theoretical foundation of the reform of Higher Vocational English teaching and multimedia teaching. 


\section{The feasibility and necessity of network application in College English Teaching}

Multimedia and network technology has unparalleled advantages of other technologies. As is known to all, it can provide friendly interface, visual image interactive learning environment, can provide graphic audio-visual articals variety of sensory stimulation, can according to hypertext, hyperlink way of organization and management of knowledge and a variety of teaching information, in Internet organized by way of the construction of the knowledge base, information base voluminous, has become the biggest source of information in the world, and to the formation and development of students' cognitive structure, namely, the promotion of students about the meaning construction of knowledge of the current study is very favorable. It will also explore new teaching mode provides to the teaching environment. At the same time, due to network originated in the United States, online resources in English is one of the major languages in, so online has rich English information and resources[3], which virtually for English teaching than other disciplines more learning resources and environment. We all know that foreign language teaching should be students listening, speaking, reading, writing, translation and other aspects of skills and imparting cultural background knowledge of English speaking countries, and provided by Internet e-mail, BBS, chat room, virtual classroom provides a very good resources, environments and tools for the cultivation of the ability. In addition, we are exploring the network is applied to college English Teaching in the main reason: first, after college students in primary school and middle school English learning with some listening, speaking, reading, writing and translation ability, its processing English information to create the conditions; second, their autonomy and autonomous learning ability is strong. Third, they knowledge of computers and the Internet also certain understanding and application ability.

\section{How to realize the effective integration of network and College English Teaching}

Under the network environment the teaching resources are open; the communication media is the multi direction communication; the transmission system is the multimedia; the knowledge is the limit of time and space. This feature determines the teaching process in the network environment is: openness; interactive learning process; learning content selection of autonomy and personalization; content form of multimedia. In such a teaching process, students will be bound to learn the loose, uncertainty and difficult to control. In the environment of multimedia network classroom computer and discipline integration is to classroom teaching time as constraint variables, the level of gifted students are learning speed index, strong ability of students to complete the learning tasks in less time, student learning is actual learning time varying with the time variation of a function, as long as there is enough time, can reach the required level. But the actual situation is, we could not to did not reach to grasp students unlimited extended learning time, but to take other means such as provide personalized help, students between collaboration, tutoring and other relative to extend the learning time of students. Now with celebrations Holiday this unit as an example to illustrate the specific teaching process.

1) create situations, put forward questions, stimulate interest, and guide students to learn. The teacher chose the theme of "Celebrating the festival" according to the contents of the unit. Just as the students' favorite Christmas is coming, everyone is busy getting ready for Christmas gifts. Teacher this is the theme of advance to the layout of the students learning task, let them through the network to understand the western countries to celebrate Christmas, and with the Chinese Spring Festival is compared, knowledge in Chinese and Western culture, and what are the differences. Then according to the text of the topic and the topic of interest to students divided into sub tasks: teachers will be a reasonable mix of students, divided into several groups. Each group choose their own interest in a task from each sub task (can go to different countries for Christmas)[4].

2) groups of students to collect the teaching information, learning process teachers monitor students, learning disabilities students to judge, to provide personalized help. The students in groups according to the task requirements of the Internet to collect information about christmas. The cyber source is very rich, a student may be at a loss what to do, the teacher can give some targeted web 
site, guide the students to focus on the relevant information and solve problems. Collect the information in each group under the leadership of leader, and the information collected is compiled, and understanding and learning. The students in the process of collecting information in the Internet, may encounter difficulties, can be timely feedback to the teacher by "electronic hands" etc.. The teacher uses the network system to answer student questions, observational learning, individual counseling screen.

3) discussion, cooperation and exchange, enrich the knowledge of the research problem. Students downloaded information, via FTP the results aggregated to the head of the machine group of the collected information and data group discussion and communication, to reach a consensus, the formation of a written materials about the research content and presentation materials. Teachers should conduct macro-control on the research content, so that each team is sure to make the report and display content. The class has a home, according to the different topics link to each group online. The demonstration for students in Teachers' guidance. Each team can choose display mode: report, interview, will report the results of each group of organic together through the whole class homepage. Finally, through a questionnaire survey to help students understand each group about the contents of the research, knowledge collection, resource sharing.

4) the typical review of the learning activities of students, cooperation to complete the construction of meaning. The students work appraisal method can take student peer assessment and teacher review. Teachers should be in positive result while the deficiencies to be added. At the time of review, attention should be paid to the dynamic evaluation of the whole research process, rather than the traditional summative assessment in teaching. At the same time, teachers should also induce students to others learning outcomes and group members in the cooperative role in the process of discussion and evaluation. Thus, students have formed their views through "human-computer interaction" and "communication", construct their own cognitive structure "".

In the process of teaching, students can not only learn more knowledge, get more information, learn more about the difference between Chinese and Western culture, and all aspects of their ability to receive training and training students to English in Internet search information, material, can cultivate the reading comprehension ability, the ability to search for information; the exchange of information by e-mail with teachers and classmates, can exercise the ability of using English to communicate with the group as a unit; discuss and organize information, report writing ability, they can be innovative thinking and the spirit of cooperation[5]; the demonstration, can improve the ability of oral expression; listen to show results can improve the hearing. The students are more interested in learning English, more active in learning English, the main role of the students further play, thus greatly improve the learning efficiency.

\section{Conclusion}

Based on the practice of College English teaching model in network, so far has been carried out for a year and a half, effect is ideal, students enthusiasm high, autonomous learning ability, innovative consciousness and cooperative learning ability has improved, especially students with a good foundation, they have strong search ability of learning materials and information, management regulation of learning activities to ensure the high efficiency of learning, they are the beneficiaries of the new teaching mode. Poor English students will encounter more difficulties in learning, they lack confidence in autonomous learning, teachers should give more guidance and attention to them, enhance their self-confidence.

\section{References}

[1] Gu. Internet English - World roaming Peja Internet assisted English teaching [M]. Shanghai: Shanghai foreign language education press, 1998.

[2] Deng Xinghui. [J]. foreign language teaching and foreign language teaching based on multi media perspective, 2003 (9). 
[3] Zhang Xiaoying, Li Tianxian. Constructivism and Multimedia Computer Assisted College English teaching [J]. foreign language teaching, 2003 (2).

[4] he Kekang. Construction of the theoretical basis for the doctrine of information technology teaching reform in higher education [Z].1997 in Hong Kong "education skills and Technology Conference" special report.

[5] Chen Li, Chen Li, Chen Meiling. Network based classroom teaching and instructional design [J]. China audio visual education, 2002 (4). 